\title{
10 health stories that mattered: Nov. 1-7
}

- The federal government has restored temporary access to basic health care for refugees to comply with a Federal Court decision from July. The government intends to continue to fight the court's decision that its cuts to refugee health care are unconstitutional.

- Canada will give another \$30.5 million to help fight Ebola but will not be sending medical personnel to West Africa. Most of the money, \$23.5 million, is dedicated to testing the Canadian-made Ebola vaccine and the experimental treatment ZMapp.

- The World Health Organization (WHO) has questioned Canada's decision to limit inbound travel from West African countries struggling with Ebola. Recent decisions to halt the processing of permanent residency visas and to not issue new visas are stronger measures than recommended by the WHO, thereby contravening the International Health Regulations.

- Canada has rejected visa applications for an adopted baby girl from Ebola-affected Sierra Leone, prompting the child's new father to apply for a visa from the United Kingdom, where he is also a resident. The man, who lives in Quebec, plans to reapply for a Canadian visa from the UK to avoid the ban on visas for residents from countries affected by Ebola.

- The Children's Hospital of Eastern Ontario has initiated court challenges to patents on human genes. The hospital argues that the patents restrict access to genetic information, which undermines medical research and patient care.

- Health Canada has been publishing research and regulatory documents in a journal run by a "controversial Croatian online publisher" that is featured on a list of "predatory publishers," reports the Ottawa Citizen. Many of the articles in the online journal, the International Food Risk Analysis Journal, are written by Health Canada but don't undergo external peer review at the journal.

- The open-access online medical journal Open Medicine is closing. The journal strived to disseminate unbiased medical research and discussion, but budget limitations and difficulties in attracting authors and editors have made it unsustainable, stated the journal's final editorial.

- There is no evidence of a link between exposure to wind turbine noise and negative health effects, according to a preliminary analysis of a Health Canada study of data from residents of Ontario and Prince Edward Island. Exposure to wind turbine noise was found to have no association with quality of life, sleep quality, stress, chronic pain, high blood pressure, heart disease or other illnesses. However, the turbines were statistically associated with residents being "very or extremely annoyed" for 12-plus months about wind turbine noise, shadow flicker, blinking lights, vibrations and visual impact.

- The recent killing of a soldier in Ottawa was the result of an "explosive cocktail" of mental health problems, drug addiction and extremistinspired ideology on the part of the alleged perpetrator, stated Public Safety Minister Steven Blaney. The girlfriend of the deceased soldier has also laid the blame for the tragedy on the "dismal state of mental health care" in Canada.

- New Age Medical Solutions Inc. of British Columbia is pursuing a court challenge of Health Canada's decision to deny the company a licence to sell medical marijuana. The application was rejected because the company didn't have an acceptable quality-assurance specialist. Roger Collier, CMAJ

CMAJ 2014. DOI:10.1503/cmaj.109-4938 